\title{
Everyday Problems of an Obese Person
}

\author{
Jonida Haxhiu \\ Institute of Public Health, Rruga "Aleksandër Moisiu" nr 80, Tiranë, Albania \\ Email: jonidahaxhiu@yahoo.com
}

Doi:10.5901/mjss.2014.v5n23p1813

\begin{abstract}
Backround: Obesity is one of the biggest problems related to health in the days we live. This situation usually goes on for a long time, making it difficult to even more its management and treatment. Not unfairly, it is often considered as a chronic disease, just because of the duration, which even more complicates the problem. Purpose: This study aims to understand the everyday life at obese persons, in order to explore their life, to understand their impulses, what pushes and reinforces this behavior, which makes it difficult or life style modification. Methodology: It is intended to undertake a qualitative research, precisely in order to penetrate and to better understand the everyday life of obese persons, to understand the problems that accompany obesity and relate tos to it. Participants were 5 women and 2 men, aged 23-45 years, recruited from weight loss programs in which they were registered. It have been conducted case studies and a focus group with these people. Were also studied the personal files, because these people had health problems related to obesity. Results: The study found that obese people have unhealthy food habits. So they eat hipercaloric foods, often consume large amounts of food, are not included in physical activities, etc.. In most cases, for most of the negative aspects associated with obesity, obese people report that they are aware of them, but are difficult to change. Conclusions: Obesity is a behavior associated highly with living habits. Having been so, it severely hampered an effective involvement in efforts to change these habits and therefore to change lifestyle and to attempt to reduce or solve the problem of obesity.
\end{abstract}

Keywords: obesity, life habits, eating behavior, hipercaloric food

\section{Introduction}

The traditional goals of obesity treatments are to reduce body weight, maintain a lower body weight over the long term, and prevent further weight gain. Because effective, sustained weight loss is not easily achieved, medical treatment, including surgery, is offered to morbidly obese people.

The American Psychiatric Association has never regarded overeating or excess weight as a psychiatric disorder, and most obese people do not qualify for a psychiatric diagnosis. Accordingly, most studies do not find a clear association between mental health and weight.

But with the abundance of overweight people, there is plenty of room for exceptions. Some research suggests that depressed persons are more likely to develop the metabolic syndrome that often accompanies excess weight, especially when this weight is concentrated around the waist. People may console themselves with "comfort food", which is usually high in fat, sugar, and calories because they are anxious, lonely, angry, or suffering from low self-esteem. There is a characteristic type of depression with symptoms that include lethargy and overeating. Like most mind-body interactions, obesity can lead to ill health, which is linked to depression and anxiety.

Additionally, overweight people are also more likely to lose the psychological benefits of exercise. If they feel rejected, unattractive, or suffer social discrimination, the emotional strain may cause further weight gain. The problem is worse if they fail to lose weight and are blamed (or blame themselves) for lack of self-control.

In a Swedish study, women reported greater psychosocial problems in everyday life on an obesity-specific measure of Health Related Quality of Life, but not in a generic one. Other studies examining sex differences in bariatric surgery patients found no differences . In a recent study using survey data from a US national sample, both mental and physical Health Related Quality of Life were worse in obese women, but only physical Health Related Quality of Life was worse in obese men than in men of normal weight.

A literature review has emphasized the importance of increased activity as part of lifestyle behavior for obese patients . Andersen et al. (2010) found employment to be positively related to quality of ilfe in morbidly obese persons. A study of 143 treatment-seeking morbidly obese reported that the physical and mental scores of the Short-Form-36 Health Survey (SF-36) were significantly higher in the employed group than the unemployed group [18]. 
Despite ongoing efforts to promote a healthy lifestyle, to maintain an optimal weight, or to reduce weight, is still is a pretty obvious problem. This poses the question what factors influence the daily lives of these persons. What are the daily habits of these persons, where obesity is already a dangerous situation. Habits can be defined as repeated behavior, not reflective, a basic need which helps to manage daily life. Habits often associated with problematic behavior, including, addictions, abuse, obesity, etc. (Lindbladh \& Lyttkens, 2002). Habits are often seen as an intimate part of yourself and the liaison at the same time, is what connects private self with others, with the rest of the world (Connerton, 1989). According to Merleau-Ponty (2002) body in which we live is a full body habits.

In sociological context, a goal-oriented version of rational behaviour is divided by the daily practice routine, which does not require any reflection on the goals, motivations and meanings (Berger \& Luckmann, 1966; Connerton, 1989). However, in the context of everyday life, it is very difficult to separate the customary behavior from the reasoning. Also, it is clear that there are significant differences in terms of the way in which people relate to the habits (Lindbladh \& Lyttkens, 2002). These researchers suggest that people in lower social positions, are more connected with their habits and are less likely to change their behavior.

Several studies conducted with obese persons, have emphasized this very strong link that exists between their habits of eating and obesity. In a qualitative study in Denmark showed that obese people were aware of food and related consequences, but despite this, make choices contrary to their knowledge (OVERGAARD, 2002).

\section{Methodology}

It is intended to undertake a qualitative research, precisely in order to penetrate and to better understand the daily lives of obese persons, to understand the problems that accompany obesity and linked to it. This is intended as a method that allows participants to talk about what they do or think regarding obesity as a major problem in their lives. Qualitative studies have become an accepted methodology within health research. Advocates note the strength of qualitative methods in delivering a greater depth of understanding of, for example, the complex phenomena faced by patients living with long term conditions. Core definitions of qualitative research point up the value of flexibility within an emergent design in which textual data are acquired to explore social phenomena in context.

Participants were 5 women and 2 men, aged 23-45 years, recruited from the weight loss programs in which they were registered.

It have been conducted 7 case studies and a focus group with these people. Were also studied the personal files, because these people had health problems related to obesity.

\section{Results}

This study attempted to explore the quality of life of an obese person, their nutritional habits, and some practical consequences directly related to these habits.

It is found that obese persons have life habits that are generally not consistent with a healthy lifestyle, particularly those that help to maintain a normal body weight. So the participants accept that they have unhealthy eating habits. So, they eat unhealthy, hipercaloric foods, eat large quantities or are involved in binge eating episodes. Also, participants agree that they are not included in physical activity. They also report that they have a range of psychological consequences related to these habits. So they feel bad, think negatively about their appearance, etc..

Obesity is a situation that creates a lot of stress on the individual, stress which in most cases can push towards food, which is a vital habit that is considered very difficult to change.

\section{Discussion}

Being severely obese has serious psychological and social repercussions. Many people who are overweight are subject to disapproval, even lectures, from family and friends and to sneers and remarks from strangers. Such behavior is propagated by the general societal belief that obesity is caused by a lack of self-discipline or moral weakness. These attitudes carry over into the work world, where a job or a promotion is often denied simply because of how much one weighs. All this are reported from participant as the others don't understand them, that this problems make them feel bad about perceiving themselves as an obese people. They tend to consider obesity as an attitude, as part of their life, and for them is so difficult to change this.

The environmental factors of perceived social support, refers to the belief that help will be available from close persons if needed. In obese youth, perceptions of social support are significant predictors of overall psychological well 
being Although social support has rarely been studied in the adult obese population, Wiczinski et al. (2009) demonstrated that social support was significantly associated with better physical and mental. According to the buffering model of support, social support is beneficial because it decreases the negative effects of stress on both mental and physical health. Participants in this study admit they have social support, but others don't understand them in a fully manner. They need someone who understand their specific problems. Their friends or relatives try hard to support them, but in general they dint understand them, how they feel.

Personal factors comprise internal aspects such as self-efficacy, which may influence functioning. There is empirical evidence that self-efficacy is a possible mediator in improving lifestyle change, but not quality of life in obese people. The participant report that they don't feel good with theirself, they don't like theirself. Most of them think that they cannot lose weight because their problem is so big and they are so weak.

I see myself as a person obese. This is a very important aspect that accompanies obese persons, almost at any moment. The participants in the study admit that even when they do not have the mind to obesity as an accompanying phenomenon, they remember when they eat something, remember when to dress, when to buy clothes, when I see in a different way, the views "different" when they eat, etc...

Eda says, "I realized that I had started with an weight problems, when I started to have problems to move. This resulted in reducing walking because of this discomfort. Gradually, I understood that it was hard to move and hard to breathe. This interrupts me in my daily life. "Obesity is associated in most cases with a range of health problems, such as hypertension, blood fats, arrhythmia, etc.. Also, physical activity is reduced in obese persons, precisely because of the movement is full of discomfort. The participants say that not only weren't involved in regular physical activity, but also had reduced the physical activities that were involved, precisely because of this uneasiness. This discomfort comes from the excessive kilos and effort to move a large body mass, but also by physical problems related to movement, such as heart rate, breathing problems, which make it difficult further exercise of physical activity.

"What to wear?" constitutes a major problem, which definitely has a considerable psychological impact on obese people. Aida says "I feel down when my friends discuss about clothing, discuss the models, or about fashion. It seems like a thing that i love but could never reach it, never will I can never dress like them, be dressed with beautiful clothes, or to look beautiful. I should just wear those ugly clothes with very large measure, that hard to find, that definitely cannot ever look beautiful". The participants admit all that dressing is a big problem for them. It is very hard to find clothes that they like or even more difficult to find trendy clothes. They are limited in quantity; they have to go where there is large size and there to find something that may be okay.

Also sweating, which is another stress itself. This further limits, limit the range of clothing of obese persons, which is reported by all participants in the study. Not only shapes and dimensions should be considered but they must also be more hygienic materials, because sweating is multiplied in them. Valbona says "sweating is one of the biggest problems for me, especially in the summer, but that starts just when it warms a bit. However even in the winter, I find, because all rooms are heated. It seems to me that it smells horrible. "

To see myself as a obese person is linked with great disappointment, especially for women. Suela says "whenever I fell stressed when i stand before the mirror. It stress me out so much of this ugly owl, that makes my live so horrible. I im bored from it. I even curse it. I try to steer as little as I can in the mirror". All participants in the study admit that they feel so stressed when they think of their appearance, that grieved when everyone first perceive them as obese, with all the prejudices associated with this, and then the really persons they are. Being In public, is very fastidious for obese persons. Eda says 'I feel very uncomfortable being with others. All they people, look at me me, as I was an alien'. Arti says, "I know that all girls which I may be in contact in the beginning see me as an obese person. Most of them concentrate here all conversation. This stressed me a lot, but somehow I started to get used to. I understand that it is normal for them. I'm different, I'm much more pounds than people they know, I am twice the other persons are. Even with females with which communication is consolidated, the theme of my obesity appears to be the favorite one. "

The nurturing. Participants acknowledge that eating is one of the greatest pleasures in life. All said they always had a good relationship with food. Nutrition has been a very important process in their lives. They also admit that their preferred foods are "forbidden" foods such as fast food, those with fats, sweets, etc.. And they continue to prefer them...

Participants reported that being obese is very difficult. It is very hard to be in physical activities because, fatigue, sweating and greatly create a lot of problems. Also it makes them think they need to eat. And in most cases, justified by the fact those weights are great and if you do not eat, can have a problem.

Also eating, as the greatest satisfaction in their lives is the best reward for them. If something goes wrong, the best way to reward you is just food. Also, according to them, eating is also is a pleasant substitute because they lack a lot of activities and beautiful things because of obesity. "There comes a moment, that you say enough, why should I suffer!? Why should I weaken and torture myself? And I eat like a crazy that moment, says Eda ". 
Also the nurturing is also a facilitator for the endless suffering associated with being obese. "When I'm upset, I eat even more What else can I do? Cry, droop, and finally I eat if I were crazy as to fill the gap and bad taste in my soul-says Valentina ".

\section{Conclusions}

The participants in the study admit that obesity is a phenomenon that accompanies all the time.

Also, physical activity is reduced in obese persons, precisely because of the movement uneasiness.

Not surprising, obese people prefer not to go out in public because they feel self-conscious or they simply cannot enjoy activities that most people take for granted, like going to the movies, taking the subway, or going on vacation because the seats are too small, the turnstiles are too narrow, or the accommodations are too uncomfortable. All these experiences, repeated day after day for years, can lead to depression, anxiety, or low self-esteem,. and mental illness.

The nurturing. Participants know that eating is one of the greatest pleasures in life.

Participants reported that being obese is very difficult. It is a hard thing to be in physical activity because, fatigue, sweating and greatly creates a lot of problems,

\section{Recommendations}

It is important that obese people have as much information about obesity, what influences and reinforces it. If they will be readily understand that obesity is a habit and if we substitute it with other habits, or reduce, it would be much simpler management of this problematic situation for them.

\section{References}

Fontaine K, Cheskin L, Borofsky E. Health-related quality of life in obese persons seeking treatment. J Fam Prac 1996; 43: $265-270$.

Katz DA, McHorney CA, Atkinson RL. Impact of obesity on health-related quality of life in patients with chronic illness. J Gen Intern Med 2000; 15: 789-796.

Myers A, Rosen J. Obesity stigmatization and coping: relation to mental health symptoms, body image and self-esteem. Int J Obes Relat Metab Disord 1999; 23: 221-230.

Doll HA, Peterson SE, Stewart-Brown SL. Obesity and physical and emotional well-being: associations between body mass index, chronic illness, and the physical and mental components of the SF-36 questionnaire. Obes Res 2000; 8: 160-170. Fontaine KR, Bartlett SJ, Barofsky I. Health-related quality of life among obese persons seeking and not currently seeking treatment. Int J Eat Disord2000; 27: 101-105.

National Institutes of Health/National Heart, Lung and Blood Institute. Clinical guidelines on the identification, evaluation and treatment of overweight and obesity in adults-the evidence report. Obes Res 1998;6(Suppl): 51S-209S. Centers for Disease Control and Prevention. Measuring healthy days. CDC: Atlanta, Georgia; November 2000.

Centers of Disease Control and Prevention. Health-related quality of lifeamong persons with epilepsy-Texas, 1998. MMWR 2001; 50: 24-26, 35.

Newschaffer CJ. Validation of Behavioral Risk Factor Surveillance System (BRFSS) HRQOL measures in a statewide sample. CDC: Atlanta; 1998.

Idler E, Benyamini Y. Self-rated health and mortality: a review of twenty-seven community studies. J Health Soc Behav 1997; 38: 21-37.

Ford E, Moriarty D, Zack M. Self-reported body mass index and health-related quality of life: findings from the BRFSS. Obes Res 2001; 9: 21-31. Flegal KM, Carrol MD, Kuczmarski RJ, Johnson CL. Overweight and obesity in the United States: prevalence and trends, 1960-1994. Int J Obes Relat Metab Disord 1998; 22: 39-47.

Mokdad A, Serdula K, Dietz W. The spread of obesity epidemic in the United States, 1991-1998. JAMA 1999; 282: 1519-1522.

Levy AS et al. Weight control practices of US adults trying to lose weight.Ann Intern Med 1993; 119: 661-666.

French SA, Jeffery RW, Murray D. Is dieting good for you? Prevalence, duration and associated weight and behavior changes for specific weight loss strategies over four years in US adults. Int J Obes Relat Metab Disord1999; 23: 320-327.

Stewart A, Brooks R. Effects of being overweight. Am J Public Health 1986;76: 1410-1415.

Mathias SD, Williamson CL, Colwell HH. Assessing health-related quality of life and health state preference in persons with obesity: a validation study. Qual Life Res 1997; 6:311-322.

Rothblum ED. The relationship between obesity, employment discrimination and employment related victimization. J Voc Behav 1990; 37: 251266.

Brownell KD. Execise and obesity treatment: psychological aspects. Int J Obes Relat Metab Disord 1995; 19(Suppl): S122-S125.

Wing RR, Epstein LH, Marcus MD, Kupfer DJ. Mood changes in behavioral weight loss programs. J Psychosom Res 1984; $28: 189-196$.

Stein AD, Lederman RI, Shea S. The Behavioral Risk Factor Surveillance System Questionnaire: its reliability in a statewide sample. Am J Public Health 1993; 83: 1768-1772.

Jackson C, Jatulis DE, Fortmann SP. The Behavioral Risk Factor Survey and the Stanford Five-City Project Survey: a comparison of cardiovascular risk behavior estimates. Am J Public Health 1992; 82: 412-416. 